\section{World Stroke Day — October 29, 2016}

The theme of World Stroke Day 2016 is "Face the Facts: Stroke is Treatable," highlighting that lives can improve with better awareness, action, and access. Stroke is a leading cause of disability and the second leading cause of death worldwide $(1,2)$. In the United States, one person dies every 4 minutes from stroke, and up to $30 \%$ of stroke survivors are permanently disabled (3). High blood pressure is a leading risk factor for stroke (3).

This year's World Stroke Day campaign aims to raise awareness that stroke is a medical emergency and should be immediately treated. Stroke is a complex medical condition, but there are ways to reduce its complications. Recognizing the signs of stroke and acting FAST (face drooping, arm weakness, speech difficulty, time to call 9-1-1), promoting awareness of specialized stroke units, and providing rapid access to proven treatments (e.g., thrombolytic drugs) improve the chances for recovery. The campaign encourages everyone, including health care professionals, to push for improved stroke care. Physicians and nurses can encourage more education about stroke among hospital staff members, and emphasize the benefits of specialized stroke units, which increase the chances of a patient having a good outcome after a stroke (4).

Approximately $80 \%$ of strokes are preventable. Controlling blood pressure and cholesterol levels, and living a healthy lifestyle (e.g., exercising regularly, eating more fruits, vegetables, and foods low in sodium, and avoiding smoking) can reduce a person's chance of having a stroke.

CDC supports several public health measures that address stroke, including the Paul Coverdell National Acute Stroke Program (PCNASP) and the Million Hearts initiative. The PCNASP funds nine state health departments that measure, track, and improve the quality of stroke care. Million Hearts, coled by CDC and the Centers for Medicare \& Medicaid Services, aims to prevent 1 million heart attacks and strokes by 2017 .

More information on World Stroke Day is available at http:// www.worldstrokecampaign.org/. Information about CDC's programs to prevent stroke is available at https://www.cdc. gov/stroke/cdc_addresses.htm.

\section{References}

1. Lozano R, Naghavi M, Foreman K, et al. Global and regional mortality from 235 causes of death for 20 age groups in 1990 and 2010: a systematic analysis for the Global Burden of Disease Study 2010. Lancet 2012;380:2095-128. http://dx.doi.org/10.1016/S0140-6736(12)61728-0

2. Murray CJ, Vos T, Lozano R, et al. Disability-adjusted life years (DALYs) for 291 diseases and injuries in 21 regions, 1990-2010: a systematic analysis for the Global Burden of Disease Study 2010. Lancet 2012;380:2197-223. http://dx.doi.org/10.1016/S0140-6736(12)61689-4

3. Go AS, Mozaffarian D, Roger VL, et al.; American Heart Association Statistics Committee and Stroke Statistics Subcommittee. Executive summary: heart disease and stroke statistics—2014 update: a report from the American Heart Association. Circulation 2014;129:399-410. http:// dx.doi.org/10.1161/01.cir.0000442015.53336.12

4. Stroke Unit Trialists' Collaboration. Organised inpatient (stroke unit) care for stroke. Cochrane Database Syst Rev. 2013;(9):CD000197. http:// dx.doi.org/10.1002/14651858.CD000197.pub3 